\title{
Effect of a Pumped Storage Plant on the Generation Reliability of the Taiwan Power System
}

\author{
YUAN-YIH HSU and I-WEI TAO \\ Department of Electrical Engineering, National Taiwan University, Taipei (Taiwan)
}

(Received April 3, 1986)

\section{SUMMARY}

A novel approach to the reliability analysis of a power system with both hydro and pumped storage plants is presented in this paper. The proposed method is based on the concept of peak shaving for the hydro and pumped storage units. Different values of the stored energy of the pumped storage units are employed to demonstrate their effect on the generation reliability of a power system. The proposed scheme has been applied successfully to the reliability analysis of Taiwan power system.

\section{INTRODUCTION}

Many power companies face the problem that the daily peak load demand of the system is much higher than the base load. As a result, many expensive reserve units have to be installed to meet the load demand of the peaking hours which last for only a very short period in a year. The situation in the Taiwan power system is particularly bad because the capacities of the three nuclear plants in commercial operation, which are usually used as base-load units, amount to a large percentage of the total capacity of the system. As a result, a great amount of power flows over the EHV transmission line from the northern and southern areas, where the nuclear plants are located, to the power-deficient central area. It has been found that dynamic instability may result from this heavy power flow during the off-peak period [1].

In view of the deficiency of power in the central area during the off-peak period and the need to instal a new generating plant to improve the ever-worsening reliability of the system with the increasing load demand, a pumped storage plant is scheduled to be commissioned in the near future.

The purpose of this paper is to examine the effect of this pumped storage plant on the generation reliability of Taiwan power system. The peak-shaving method is employed to make a cost/benefit evaluation of varying the storage capacity of the plant.

\section{THE METHOD OF EFFECTIVE LOAD}

In this section, we briefly review the method of effective load $[2,3]$ for the calculation of the loss-of-load probability (LOLP) which is the index usually employed in generation system reliability evaluation. It is defined as the probability that the load demand will exceed the available generating capacity and is given by

LOLP $=P_{\mathrm{r}}\left(Z_{\mathrm{s}}<L\right)$

where $L$ is a random variable signifying the system load, $Z_{\mathrm{s}}=\sum_{i=1}^{n} Z_{i}$ is the overall available capacity of the system, $Z_{i}$ is the available capacity of generator $i$ and $n$ is the number of thermal plants in the system. Let $X_{0}=L$ be the actual load and $X_{i}, i=1,2, \ldots, n$, be the outage capacity of generator $i$, then it is obvious that $X_{i}$ and $Z_{i}$ are related by

$X_{i}=C_{i}-Z_{i}$

where $C_{i}$ is the installed capacity of generator $i$.

The effective load of the system after convolving the first $i$ units $(i=1,2, \ldots, n)$ can be expressed as

$X_{\mathrm{e} i}=X_{0}+X_{1}+\ldots+X_{i}$ 
The LOLP of the system can then be computed as follows:

LOLP $=F_{n}{ }^{*}\left(C_{\mathrm{s}}\right)$

where $C_{s}$ is the total installed capacity of the system, and the modified load-duration curve after convolving the $n$ generators, $F_{n}{ }^{*}$, can be obtained in a sequence by using the recursive formula

$$
\begin{array}{r}
F_{i}^{*}(l)=F_{i-1}{ }^{*}(l) p_{i}+F_{i-1}{ }^{*}\left(l-C_{i}\right) q_{i} \\
i=1,2, \ldots, n
\end{array}
$$

where $p_{i}$ and $q_{i}$ (forced outage rate, FOR) are the availability and unavailability of generator $i$ and

$$
\begin{aligned}
F_{0}{ }^{*}(l)= & F_{\mathrm{L}}{ }^{*}(l) \\
= & \text { original load-duration curve for } \\
& \text { system load }
\end{aligned}
$$

\section{PEAK-SHAVING METHOD FOR HYDRO GENERATING UNITS}

The method of effective load can be easily extended to the reliability analysis of a system with hydro units by means of the peak-shaving technique [4-7]. Suppose we already have the effective load-duration curve $F_{n}{ }^{*}(l)$, as shown by the broken curve in Fig. 1, after convolving the $n$ fictitious random loads signifying the outages of the $n$ thermal plants, and we want to incorporate the $(n+1)$ th unit, which is a hydro plant, into the system. As shown in Fig. 1, we first compute $l_{\mathrm{h}}$ by solving

$$
\int_{l_{\mathrm{h}}}^{l_{\mathrm{h}}+C_{n+1}} F_{n}^{*}(l) \mathrm{d} l=E_{n+1} / T
$$

where $E_{n+1}$ is the energy of the hydro plant, $C_{n+1}$ is the capacity of the unit and $T$ is the

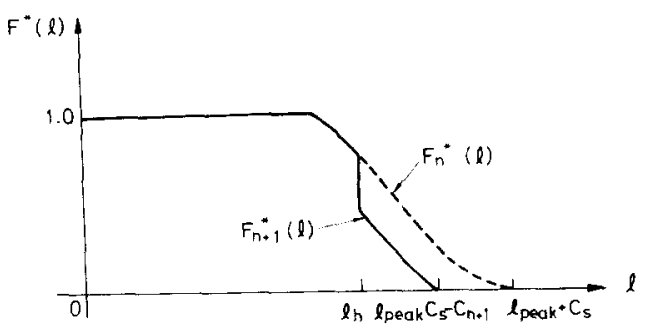

Fig. 1. The load-duration curve including the effect of the hydro unit. time interval considered in the load-duration curve (one year for the present case). Then, the curve $F_{n+1}{ }^{*}(l)$ with the hydro plant incorporated is given by

$$
\begin{aligned}
F_{n+1}{ }^{*}(l) & =F_{n}{ }^{*}(l) & & l \leqslant l_{\mathrm{h}} \\
& =F_{n}{ }^{*}\left(l+C_{n+1}\right) & & l>l_{\mathrm{h}}
\end{aligned}
$$

This modified load-duration curve is shown by the full curve in Fig. 1.

\section{RELIABILITY ANALYSIS OF A SYSTEM WITH PUMPED STORAGE UNITS}

There are two kinds of operation modes for a pumped storage unit: the pumping mode in which the unit is operated as a motor and the generating mode in which it is operated as a generator. In evaluating the effect of a pumped storage unit on the reliability of a power system, the unit is first modelled as a hydro generator as follows.

Let $C_{n+2}$ be the generating capacity of a pumped storage unit and $E_{n+2}$ be the stored energy of the unit which can be expressed as [8]

$E_{n+2}=C_{n+2} h T$

where $T$ is the time interval considered as defined before and $h$ is the number of generating hours at full capacity. For the sake of simplicity, $h$ is assumed to be a constant throughout a year. The equivalent loadduration curve after convolving the generating operation mode is given by

$$
\begin{aligned}
F_{n+2}{ }^{*}(l) & =F_{n+1}{ }^{*}(l) & & l \leqslant l_{\mathrm{g}} \\
& =F_{n+1}{ }^{*}\left(l+C_{n+2}\right) & & l>l_{\mathrm{g}}
\end{aligned}
$$

where $l_{\mathrm{g}}$ is computed from the equation

$\int_{l_{\mathrm{g}}}^{l_{\mathrm{g}}+C_{n+2}} F_{n+1}{ }^{*}(l) \mathrm{d} l=E_{n+2} / T$

For the pumping mode, the pumping capacity $C_{\mathrm{p}}$ is usually set to be equal to $1.1 C_{n+2}[8]$. Therefore, the pumping energy, $P_{n+2}$, is

$$
\begin{aligned}
P_{n+2} & =C_{\mathrm{p}} h T \\
& =1.1 C_{n+2} h T \\
& =1.1 E_{n+2}
\end{aligned}
$$


When the pumping mode is taken into account, the load-duration curve becomes

$$
\begin{aligned}
F_{n+3}{ }^{*}(l) & =F_{n+2}{ }^{*}\left(l-C_{\mathrm{p}}\right) & & l \leqslant l_{\mathrm{p}} \\
& =F_{n+2}{ }^{*}(l) & & l>l_{\mathrm{p}}
\end{aligned}
$$

where $l_{\mathrm{p}}$ is obtained from

$$
\begin{aligned}
& \int_{0}^{l} F_{n+2}{ }^{*}\left(l-C_{n+2}\right) \mathrm{d} l-\int_{0}^{l} F_{n+2}{ }^{*}(l) \mathrm{d} l \\
& \quad=P_{n+2} / T
\end{aligned}
$$

This is evident from the fact that the pumping energy in eqn. (13) can be expressed by the area of the shaded region in Fig. 2.

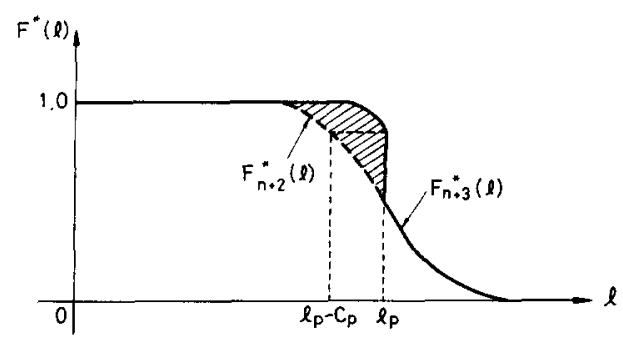

Fig. 2. The effect of the pumped storage unit on system reliability.

\section{NUMERICAL EXAMPLE}

The capacities, FORs and the number of generating units of the thermal plants in Taiwan power system are given in Table 1 .

In addition to these thermal plants, there is a hydro plant with a capacity $C_{n+1}=1431$ MW and energy $E_{n+1}=4640 \mathrm{GWh}$. The generating capacity of the pumped storage plant to be installed is $1000 \mathrm{MW}$. The loadduration curve of the load is described by

$$
\begin{aligned}
& F_{\mathrm{L}}{ }^{*}(l)=0.4521+0.15525 \times 10^{-3} l \\
& +0.11703 \times 10^{-7} l^{2}-0.53977 \\
& \times 10^{-11} l^{3}+0.25883 \times 10^{-15} l^{4} \\
& \text { for } \quad l_{\text {base }}<l<l_{\text {peak }} \\
& F_{\mathrm{L}}{ }^{*}(l)=1 \quad \text { for } \quad l<l_{\text {base }} \\
& F_{\mathrm{L}}^{*}(l)=0 \quad \text { for } \quad l>l_{\text {peak }} \\
& \text { where } l_{\text {base }}=3880 \mathrm{MW} \text { and } l_{\text {peak }}=12740
\end{aligned}
$$

\begin{tabular}{|c|c|c|}
\hline \multicolumn{2}{|l|}{ System condition } & \multirow{2}{*}{$\frac{\text { LOLP }}{0.0312}$} \\
\hline Without pumped storage pla & ant & \\
\hline With pumped storage plant & $\begin{array}{l}h=2 \\
h=3 \\
h=4 \\
h=5 \\
h=6 \\
h=7\end{array}$ & $\begin{array}{l}0.0178 \\
0.0151 \\
0.0132 \\
0.0116 \\
0.0108 \\
0.0098\end{array}$ \\
\hline
\end{tabular}

TABLE 1

System data

\begin{tabular}{cll}
\hline Unit size (MW) & No. of units & FOR $(q)$ \\
\hline 3 & 1 & 0.023 \\
6 & 8 & 0.023 \\
40 & 2 & 0.023 \\
46.7 & 1 & 0.023 \\
61.9 & 4 & 0.023 \\
71.2 & 4 & 0.028 \\
75.0 & 1 & 0.028 \\
116.6 & 1 & 0.028 \\
125.0 & 2 & 0.038 \\
200.0 & 1 & 0.053 \\
298.4 & 1 & 0.073 \\
300.0 & 3 & 0.073 \\
318.2 & 2 & 0.073 \\
350.0 & 1 & 0.083 \\
375.0 & 2 & 0.088 \\
500.0 & 6 & 0.130 \\
636.0 & 2 & 0.110 \\
985.0 & 2 & 0.110 \\
1000.0 & 2 & 0.110 \\
\hline
\end{tabular}

TABLE 2

Loss-of-load probability of the Taiwan power system

The LOLP values of Taiwan power system are summarized in Table 2 . The equivalent load-duration curves are plotted in Fig. 3.

Various values of the generating hours at full capacity $(h)$ have been employed to examine the effect of the reservoir size of the pumped storage plant on the system reliability.

It can be observed from Table 2 that the LOLP of the system will decrease to a much lower value as the pumped storage unit is added to the system. In other words, the generation reliability of Taiwan power system can be improved significantly by the pumped storage unit. Moreover, the larger the size of the reservoir, which is proportional to $h$, the better will be the system reliability. This is as expected since more peak load can be shifted 


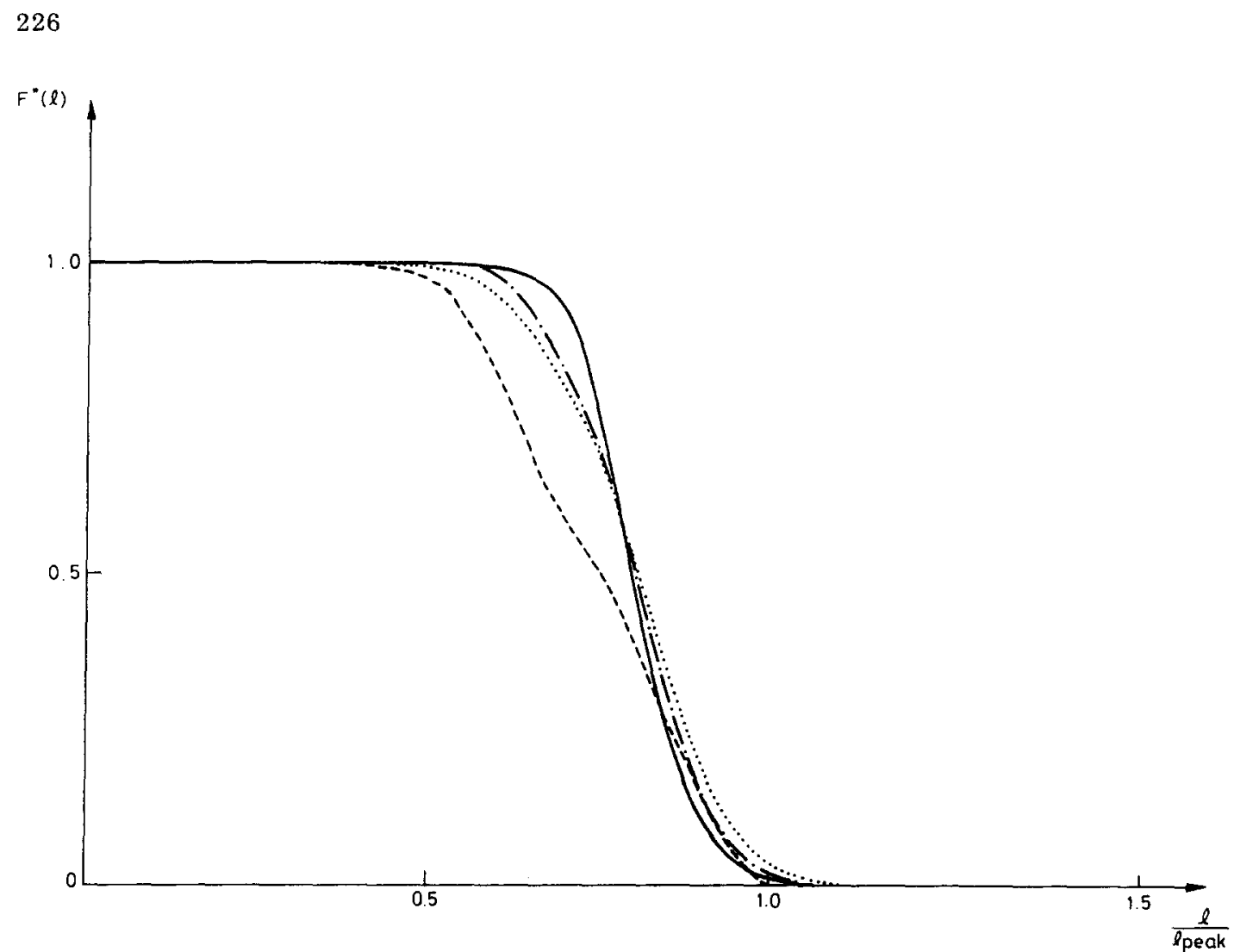

Fig. 3. The equivalent load-duration curves of Taiwan power system: - . - the original load-duration curve; ......, with thermal and hydro plants incorporated; $-\cdot-$, with thermal, hydro and pumped storage plants incorporated $(h=2) ;-$, with thermal, hydro and pumped storage plants incorporated $(h=7)$.

to the off-peak period as the reservoir capacity is increased. However, the cost will also increase with increasing reservoir capacity. There is always a compromise between minimum cost and best reliability.

\section{CONCLUSIONS}

Methods for incorporating the hydro and pumped storage plants in the reliability evaluation of a power generation system have been proposed in this paper. Results obtained from the reliability analysis of Taiwan power system show that the reliability of a generation system can be enhanced significantly by means of a pumped storage plant. Moreover, the system reliability will increase with the expanding size of the reservoir in the pumped storage plant.

\section{REFERENCES}

1 Y. Y. Hsu, S. W. Shyue and C. C. Su, Low frequency oscillations in longitudinal power system: experience with the dynamic stability of Taiwan power system, IEEE PES Winter Meeting, New York, 1986, Paper No. 86 WM 070-7.

2 Y. Y. Hsu, C. Y. Hsu and C. J. Wu, Comparison of two algorithms for power system reliability calculations, Electr. Power Syst. Res., 9 (1985) $29-35$.

3 R. L. Sullivan, Power System Planning, McGrawHill, New York, 1977.

4 E. S. Loane and C. W. Watchorn, Probability methods applied to generating capacity problems of a combined hydro and steam system, $A I E E$ Trans., PAS-66 (1947) 1645 - 1657.

5 R. Billinton and P. G. Harrington, Reliability evaluation in energy limited generating capacity studies, IEEE Trans., PAS-97 (1978) 2076 - 2085.

6 S. H. F. Cunha, F. B. M. Gomes, G. C. Oliveira and M. V. F. Pereira, Reliability evaluation in hydrothermal generating systems, IEEE Trans., PAS-101 (1982) 4665 - 4673.

7 S. T. Y. Lee and C. Dechamps, Mathematical model for economic evaluation of tidal power in the bay of Fundy, IEEE Trans., PAS-97 (1978) $1769-1778$.

8 L. Paris and L. Salvaderi, Pumped-storage plant basic characteristics: their effect on generating system reliability, Proc. Am. Power Conf., 36 (1974) $403-418$. 